\title{
Issues in Marketing Strategy Implementation
}

\author{
Nagasimha Balakrishna Kanagal ${ }^{1}$ \\ ${ }^{1}$ Indian Institute of Management, Bannerghatta Road, Bangalore, 560076, India \\ Correspondence: Nagasimha Balakrishna Kanagal, Indian Institute of Management, Bannerghatta Road, \\ Bangalore, 560076, India. E-mail: kanagal@iimb.ernet.in
}

Received: August 29, 2016

Accepted: September 13, 2016

Online Published: September 19, 2016

doi:10.5539/ibr.v9n11p16

URL: http://dx.doi.org/10.5539/ibr.v9n11p16

\begin{abstract}
Marketing Strategy Implementation (MSI) is responsible for delivering the value proposition to the customers. MSI can be seen as (1) dichotomous with marketing strategy formulation; or as (2) a mutually interdependent process along with marketing strategy formulation; or as (3) a program. Aspects postulated to be important during the implementation process include (a) presence of good leadership; (b) careful attention to the formative years of MSI program; (c) presence of trust in all important relationships; (d) system of early warning / feedback; (e) achieving functionalities in the marketing process; (f) a fetish for execution; (g) hype about rewards and incentives; and (h) choice of market vs. hierarchy. The study first addresses the placement of MSI in the strategic marketing process and the strategic organizational process, secondly examines the nature of marketing execution, and thirdly puts forth some postulates for marketing strategy implementation. These postulates are subsequently empirically checked in the market and implications for managers are subsequently laid out.
\end{abstract}

Keywords: strategic marketing process, marketing strategy implementation, trust, overcoming resistance to change, leader as integrator, fetish for execution

\section{Introduction}

Marketing Strategy Implementation (MSI) is a key process in the strategic marketing process of the organization. If marketing strategy objectives are to lead to performance results then the strategy formulation should lend itself to strategy implementation. This means that the strategy formulation should take into account the implementation obstacles to make the strategy work smoothly. Good strategy followed by good implementation leads to success, while poor strategy followed by poor implementation leads to failure. At the same time poor strategy followed by good implementation leads to average outcomes and causes trouble while good strategy followed by poor implementation leads to ruin (Bonoma, 1984). This underscores the importance of good implementation. Professor John Quelch (1992) in his HBS Note, quoted two surveys by INSEAD and Stanford University conducted in the early 1990s, that showed the 'how shall we do it' of marketing issues was more important than 'what should we do'. Some of the common issues that came out of the surveys as important issues to be addressed were - ensuring product and service quality, assessing changing customers' needs, creating a marketing culture throughout the firm. These preceding issues are to be addressed from an implementation angle rather than from a strategy formulation angle. Marketing strategy implementation is tied to the identification of the implementation process to top management. Senior positions in the organization coming from the marketing function go a long way in easing the process of marketing strategy implementation.

The components of marketing strategy implementation include (1) marketing strategy (2) shared goals and values (3) marketing organization structure (4) systems and processes (5) resources (6) people and (7) leadership. People are ultimately responsible for implementing marketing activities. Therefore the manager must be good at motivating, coordinating and communicating with all marketing personnel. The quality, diversity and skill of an organization's work force are all important considerations in implementing marketing strategy. Consequently, human resource issues are becoming more important to marketing implementation in the areas of employee selection and training, evaluation and compensation policies, employee motivation, satisfaction and commitment (Ferrell O C et al, 1998).

Thomas Bonoma of Harvard Business School proposed a framework for understanding marketing implementation issues (Bonoma, 1984). He postulated that execution could take place at any or a combination of four levels - actions, programs, systems and policies. Actions are the building blocks of execution, such as a 
sales person presenting a cooperative advertising program to an account. Programs are integrated sets of marketing actions such as an integrated marketing communications program. Systems include the firm's formal organizational monitoring and budgeting overlays which foster or inhibit getting the marketing job done. Policies prescribe whereas systems describe. Policies shape the organizational marketing theme, culture and leadership and give direction to the systems, programs and actions of a firm. Further four managerial skills that can reinforce good policies, systems, programs and actions, are interaction skills, allocation skills, monitoring skills, and organizing skills. Bonoma's framework basically includes in identifying the level of execution and the type of skill wherein lies the organization's weakness in implementation, and in rectifying them. The importance of good implementation need not be overemphasized. Implementation skills valued by distribution channels and / or end customers can be important points of competitive differentiation. The economic penalties stemming from poor execution can be substantial. Implementation skills may be more important when the competitive environment is turbulent. Implementation skills are always important, but the required mix of skills may vary from one organization to another just as the appropriate mix will vary within an organization from one execution level to another (Quelch, 1992).

\section{Method}

The study conceptually examines the placement of marketing execution / marketing strategy implementation, in the strategic marketing process of an organization; it then studies the placement of the strategic marketing process in the strategic organizational process of the firm. It then lays out the review of the literature with respect to the nature of marketing execution. Given the conceptualization of marketing execution, the study then postulates issues in marketing strategy implementation / marketing execution. These postulates are empirically verified and the study concludes with a discussion for marketing strategists. The method of study is exploratory with depth interviews to understand the challenges of marketing execution in a complex and dynamic market and business environment. Marketing Managers in charge of marketing strategy execution at (i) the marketing headquarters of Britannia Industries Ltd, Bangalore, India; the principal activity of Britannia being the manufacture and sale of biscuits, bread, risk, cakes, and dairy products; (ii) the marketing headquarters of Himalaya Drug Company based in Bangalore, India, marketing its health care products under the name Himalaya Herbal Healthcare; (iii) the marketing office of Airtel Limited in Bangalore, India. Airtel also known as Bharti Airtel Limited is a leading global telecommunications services company based in New Delhi, India, and has operations in 20 countries across Asia and Africa; the company ranks amongst the top 4 mobile service providers globally in terms of subscribers; (iv) the marketing headquarters of Laguna Clothing, a Bangalore based apparel exporter having collaborations with Monti, Italy, and Aquarelle Group, Mauritius (please see acknowledgments for timing of the empirical study). Each of the Marketing Managers, in charge of marketing strategy execution were first given an introduction of the study and they were exposed to the postulates (postulate by postulate) of the marketing strategy implementation outlined in Section 5 below. Their comments were then taken as notes; the notes of all interviews were content analyzed. The understanding of this content analysis is included in the Section 7 on Discussion.

\section{Strategic Processes}

The strategic marketing process starts with the marketing objectives. The overriding business objectives include either sales or share objective and minimization of uncertainty/risk. Some of the typical marketing objectives are - build brand equity, achieve a particular level of customer satisfaction, build awareness, achieve minimal customer complaints, promote trial.

The strategic marketing process then leads to the strategic market analysis and the internal analysis. The strategic market analysis assesses the external environment - includes customer management and analysis, market management and analysis, environmental scanning and scenario planning. The internal analysis includes the assessment of strengths and weaknesses, the resolution of constraints and the check on core competencies.

The strategic marketing process then flows into the development of marketing strategies. The development of marketing strategies gets its input from (1) strategic market analysis; (2) internal analysis; (3) analysis of past performance and current strategy; (4) analytical inputs that includes the understanding and application of competition; and (5) issues of technology choice and changing customer needs. The development of marketing strategies includes decisions on (1) segmentation and targeting; (2) differentiation and positioning; (3) market entry lexit; (4) market timing; (5) product strategy; (6) pricing strategy; (7) promotion strategy; (8) distribution strategy; and (9) functionality issues. The development of marketing strategies is followed by their effective and efficient execution - the marketing strategy implementation. The context / business environment of marketing execution includes the influences of (a) culture, (b) power, (c) technology choice, (d) change, (e) competitive 
interaction, and (f) corporate strategy and structure. This is then followed by control and feedback issues; the feedback being sent both to the marketing objectives stage and to the development of marketing strategies stage. The business marketing strategy impacts the business marketing structure and the business marketing structure in turn influences implementation results and is influenced by implementation. This is demonstrated pictorially in Figure 1.

The strategic marketing process is embedded in a larger process of the organization called strategic organizational process (Figure 2). This process (adapted from Hrebiniak, 2005), starts with the goals, vision, and mission of the organization. This is followed by the organization wide strategy also called the corporate strategy. The corporate strategy influences the organizational structure and the lead business marketing strategy. Execution of corporate strategy relies partially on the appropriate structure to support it.

The integration component of corporate structure as given in Figure 2 pertains to the methods used to achieve coordination across various units that comprise the organization. Information sharing and integration can increase the flexibility of structure and the firm's ability to execution related problems. Coordination and information sharing has to be across functions, across businesses, and across products. Such integration is possible only if the tasks, responsibilities, and accountabilities are clear. Lateral communication, transfer of knowledge across different business units within the organization is also important to execution success (Hrebiniak, 2005).

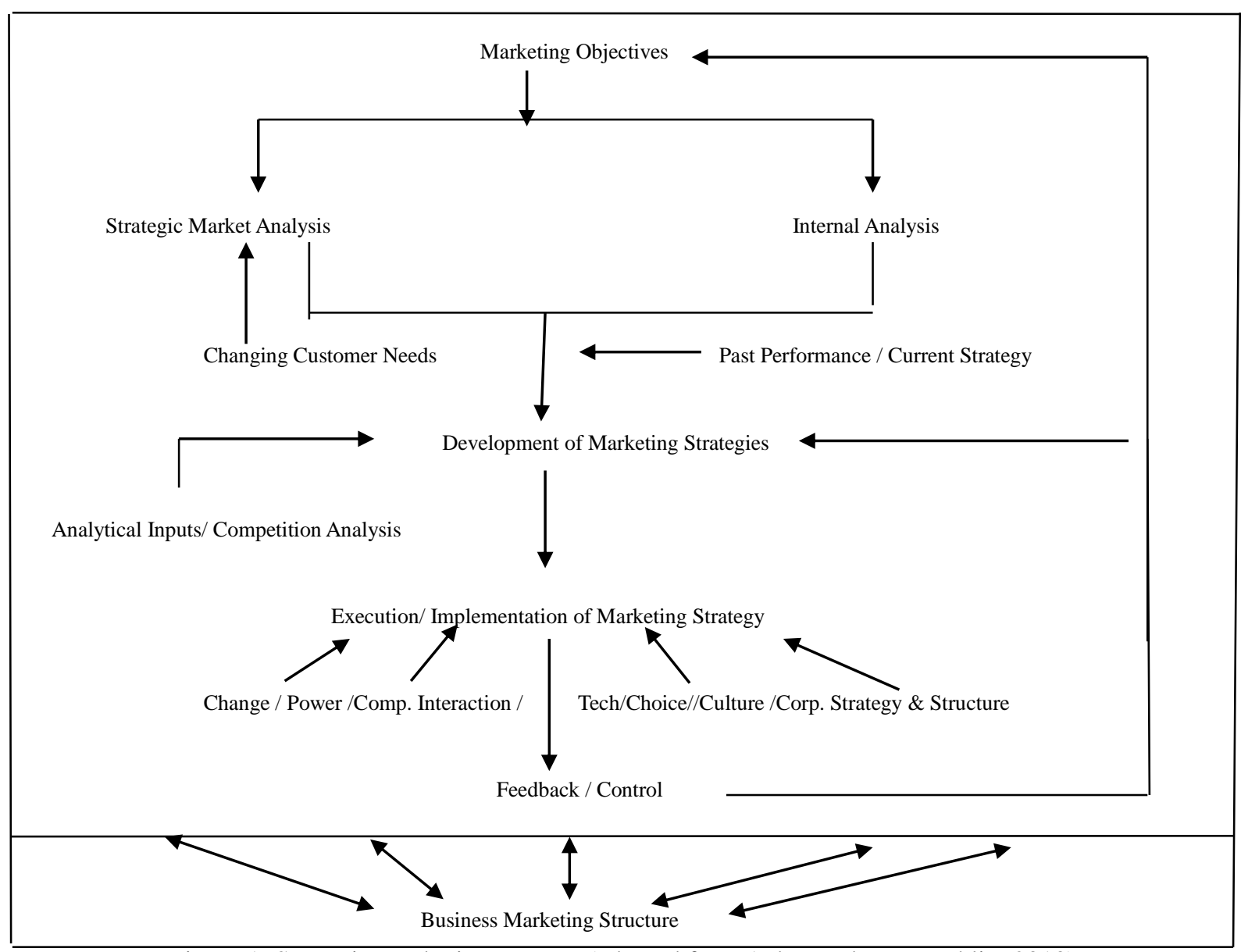

Figure 1. Strategic Marketing Process (adapted from Aaker and McLoughlin, 2010)

The corporate strategy influences the functional strategy process of functions that include manufacturing, finance, and marketing, through the short term objectives that include (a) customer satisfaction, (b) sales quotas, (c) quality measures, (d) cost controls, and (e) manufacturing downtime. Translation of strategy into short term operating objectives mentioned above that relate logically to and are consistent with business strategy is very important to execution. A business simply must ensure that everyday objectives and performance metrics are consistent with its strategic goals and plans. Business marketing strategy creates demands for organizational investments in people, technology, and other capabilities. Such investments should be made and appropriate skills developed for successful execution. The business marketing process also called the strategic marketing 
process influences the marketing functional structure. Different businesses in the same company could face different competitive situations and thus could need different organizational structures. Along with these interrelationships there could be a technology strategy that influences and is influenced by the corporate strategy. The technology strategy influences the business marketing process. It is therefore postulated in this paper that the business marketing process or the strategic marketing process is an important initial process among the functional strategies owing to the need to understand requirements of the customer and match it with the corporate strategy and technology strategy.

Along with the above interrelationships, it is necessary that for successful execution, the individual goals sub serve to group goals and there is goal congruence between individual and organizational goals. In addition there should be effective feedback so that the firm performs in the right direction. This can be achieved by appropriate incentives and controls. The incentives should reinforce strategic and short term objectives. Controls in turn, must provide timely and valid feedback about organizational performance so that change and adaptation become part and parcel of the execution effort.

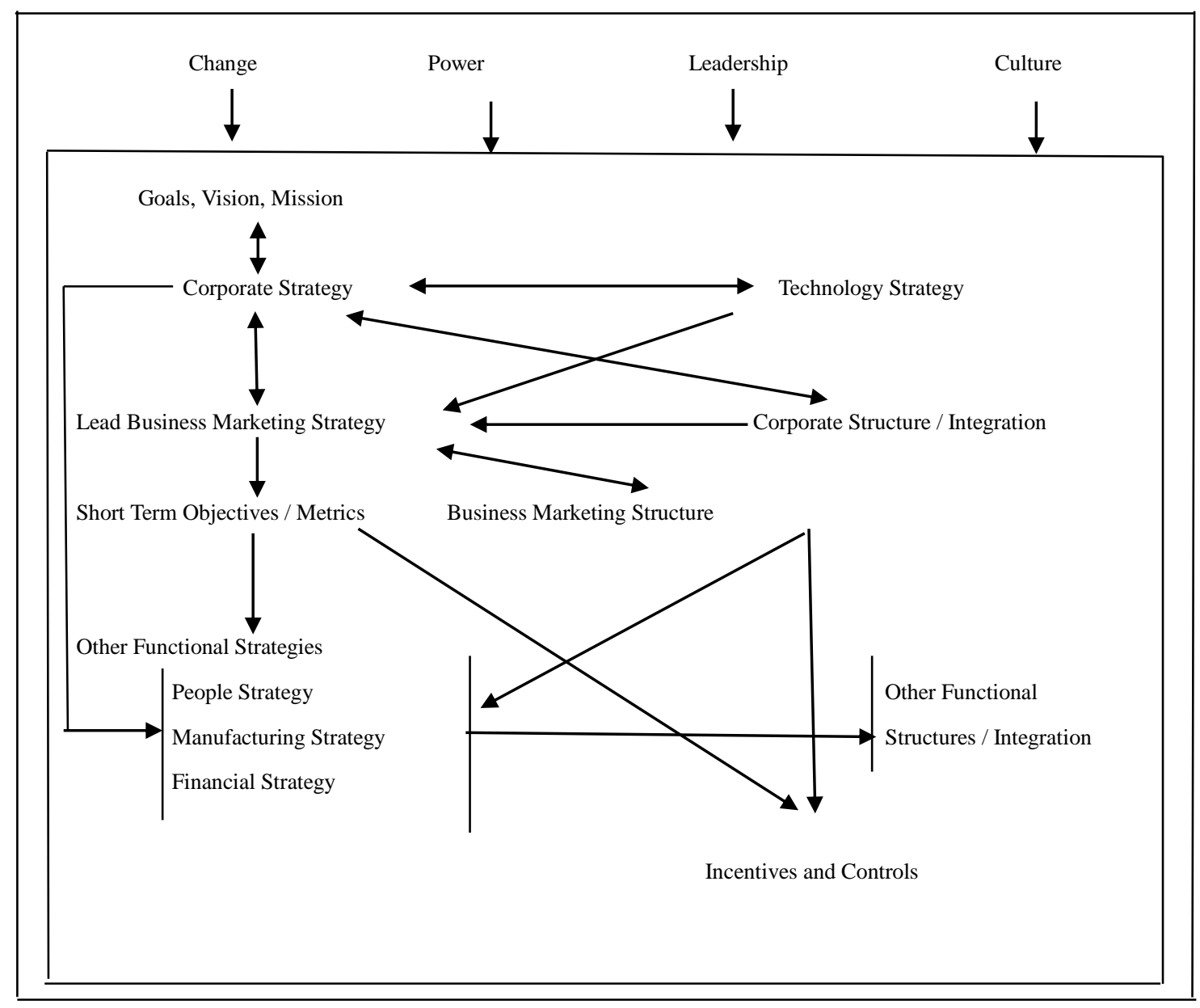

Figure 2. Strategic Organizational Process (adapted from Hrebiniak, 2005)

Business marketing strategy is important in its own right because it helps achieve competitive advantage and profits for the business unit and hence to the organization. The strategic organizational process operates in an overall context of business environment that includes (a) change, (b) culture, (c) leadership, and (d) power. Successful execution demands changes in job responsibilities, organizational structure, coordination methods, people, incentives or controls. Inappropriate cultures must be changed if they do not support organizational efforts. Power seen as the ability to solve critical problems or control of scarce organizational resources has an important influence on the creation of strategic plans and goals. People in power also affect execution success because of their resource control ability, hierarchy control ability and persuading ability. Finally leadership is an organizational context variable as leadership affects management of change, culture, and the exercise of power.

The placement of strategic marketing process (also called business marketing strategy) in the overall context of 
the organizational processes is shown in Figure 2 (Hrebiniak, 2005). Emphasis must be on what to do, how to do, when, why and in what order. The key aspects defining strategy execution thus include decisions on strategy, structure, coordination, information sharing, incentives and controls. The decisions are made in an organizational context which has aspects of power, culture, leadership and the ability to manage change. Understanding interactions among these various decision elements is important to understand execution.

\section{Nature of Marketing Execution / Marketing Strategy Implementation}

Strategy formulation and execution are separate identifiable activities or processes that are highly interdependent. Execution / strategy implementation is a specific set of behaviours and techniques that companies needs to master in order to have competitive advantage. Execution is a process. For successful execution, the need for a well-formulated strategy is of utmost importance. A host of factors, including politics, inertia, and resistance to change, can routinely get in the way of execution success. Communication across the organization becomes a challenge, especially in large organizations; the number of people involved along with the added time frames generally associated with strategy execution clearly creates problems when trying to make a strategy work. Execution demands commitment to and a passion for results, regardless of management level. Linking strategic objectives with the day-to-day objectives and concerns of personnel at different organizational levels and locations becomes a legitimate and challenging task (Hrebiniak, 2005). Some of the obstacles to strategy execution (Hrebiniak, 2005) include the following: (a) inability to manage change effectively or to overcome internal resistance to change; culture is at the core of change-related problems; in a way 'change' and 'culture change' are synonymous; culture is an underlying explanatory element in dealing with incentives, power, and change; (b) trying to execute a strategy that conflicts with the existing power structure; (c) poor or inadequate information sharing between individuals or business units responsible for strategy execution; (d) unclear communication of responsibility and / or accountability for execution decisions or actions; (e) poor or vague strategy; (f) lack of feelings of 'ownership' of a strategy or execution plans among key employees; (g) not having guidelines or a model to guide strategy execution efforts; (h) lack of understanding of the role of organizational structure and design in the execution process. The issues in implementation should be converted into a logical set of guidelines that can permeate each section of organization.

Execution (Bossidy \& Charan, 2002) consists of three building blocks - good leadership, managing cultural change, and managing the right people in the right place. Good leadership for execution consists of seven essential behaviours: (1) know your people and your business; (2) know yourself; (3) insist on realism; (4) set clear goals and priorities; (5) follow through; (6) reward the doers; (7) expand people's capabilities. An organization's culture is the sum of its shared values, beliefs, and norms of behaviour. Values are fundamental principles and rarely needs changing. Necessary cultural changes have to be made to change people's behaviour so that they produce results. This requires that a set of social operating mechanisms will change the beliefs and behaviours of people in ways that are directly linked to bottom line results. First employees are told clearly what results are important. Then a discussion is built on how to get those results. Next, there is a reward for results produced and withdrawal of rewards for results that are short. Employees then, have to be trained as necessary. If this does not create the right atmosphere, a robust dialogue is initiated among the people and leaders concerned. If this does not work the people are let go. A culture, is thus created for getting things done (Bossidy \& Charan, 2002). Having the right people in the right places is the last building block of good execution as outlined by Bossidy \& Charan (2002). This process is hindered by (a) lack of knowledge; (b) lack of courage; (c) the psychological comfort factor that leaders like to find themselves in; and (d) lack of personal commitment. Good leaders often energize and motivate people, they are decisive on tough issues, they get things done through others, and they follow through their actions.

In addition to the three building blocks of good execution described above, successful execution is said to take place when the three processes of people process, strategy process, and operations process are understood well and coherence is established between the three aforesaid processes (Bossidy \& Charan, 2002). A robust people process evaluates individuals accurately and in depth; it provides a framework of leadership and develops a basis for succession of the leadership. The people process needs to be linked to strategic milestones over the $0-2$ years, 2-5 years, and greater than 5 years' time frame. The people process should also look into handling non-performers. Further the human resource function is integrated into the people process. The strategy process deals with gaining customer preferences and creating sustainable competitive advantages, simultaneously leaving money/gain for shareholders. The strategy process must ensure that the right people are in place to execute the strategy. The strategy should deal with how to get things done. The strategy process includes the development of a strategic plan taking into account the assessment of the external environment, understanding of the customers and markets and means and methods to grow the business profitably. It is necessary in the strategy 
process to examine the competition, and the ability of the business to execute the strategy chosen and the balancing of the short term and long term orientations. A strategy process is incomplete without explicitly addressing how to make money on a sustained basis. Operating processes links strategy and people to results through the operating plan. It breaks long term output into short term targets and looks into the programs that the business will have to complete to reach the desired levels of output that includes earnings, sales, and cash flow. Synchronization between various arms of the business at the operations level is needed for smooth execution. Follow through and contingency plans are needed for successful completion of the operations process (Bossidy \& Charan, 2002).

The implementation capabilities of an organization may have the following situational conditions bearing upon it: (a) capabilities could be time specific and change with time; (b) certain implementation capabilities could be specific to the culture of that market or environment; (c) implementation capabilities may not be consistently good on all dimensions of organizational endeavor - for example they could be high on technical service but not good on customer service - thus capabilities could be partial; (d) certain capabilities may not be brought into the foreground and may remain latent due to lack of learning or management experience; (e) capabilities could be strategy specific; (f) capabilities could be person specific.

Traditional approaches to marketing implementation emphasize organizational design and manipulation of systems and structures around strategic goals (Bourgeois \& Brodwin, 1984), as well as budgeting and resource allocations systems, executive leadership approaches and control systems. Marketing implementation and formulation are treated sequentially with implementation following formulation. Corey and Star (1971) point out that strategy is influenced by structure and the balance of power within that structure; however today's structure would influence tomorrow's strategy which in turn shapes tomorrow's organization.

Recent literature brings out the process view of strategy formulation and implementation. Process could be understood in terms of its substantive content, for example the new product development process. In addition process could be conceived in terms of their purposes that are value defining, value developing and value delivering processes. Processes could be analyzed in terms of an analytic /technical dimension, a behavioural dimension and an organizational dimension. (Piercy, 1998). This is depicted in Figure 3.

An important aspect is the consistency between the analytic, behavioural and organizational dimensions of process; this consistency has an impact on implementation capabilities. Thus it could be said that marketing implementation relies more on covert aspects of the marketing organization than is commonly recognized. The process view suggests that effective strategy implementation rests not simply on techniques of action planning, budgeting, resource allocation and administrative system design; it also rests on underlying beliefs and attitudes of organizational participants, and over and above this on management interests and culture.

Some of the sources of barriers in implementation process (Piercy, 1998) are: (a) organizational inertia - the residue from previous strategies may provide an inappropriate context for the new strategy; tactics executed by one unit that is incompatible with the tactics of other sub units in the organization; such inertial forces are also called limiting commitments; (b) organizational myopia - faulty perspectives of executives that undermine commitment to a new marketing strategy; (c) resistance to change and political behaviour - problems in organizational adjustment to new strategic initiatives; (d) failures in implementation arise by design also called 'designed error,' as the organizations develop routines for implementing strategy which are taken for granted and rarely challenged; these defensive routines are overprotective of line management and strategic planners and favor the retention of status quo (Argyris, 1985); (e) information flow differences between different organizational groups could also be a source of implementation barriers; measurement systems and time horizons could vary across organizational groups, for example sales flow metrics could be on sales volume whereas product management metric could be on profit responsibility; these differing metrics cause different priorities for action that could lead to implementation barriers; (f) resistance could come from other departments in the organizations owing to their professional ideologies being different from the marketing discipline's philosophy; (g) implementation is often linked to context and the context may cause barriers to implementation, for example in a publishing environment, editors are more suitable to marketing strategy implementation of bringing out new books to the market; bringing in marketing professionals is not suitable to the context and the implementation process may face barriers from the environment; it is thus to be noted that marketing view and editorial view of a publishing environment may not always be in congruence and the secrets of the market are not exclusive property of marketers (Whittington \& Whipp, 1992). 


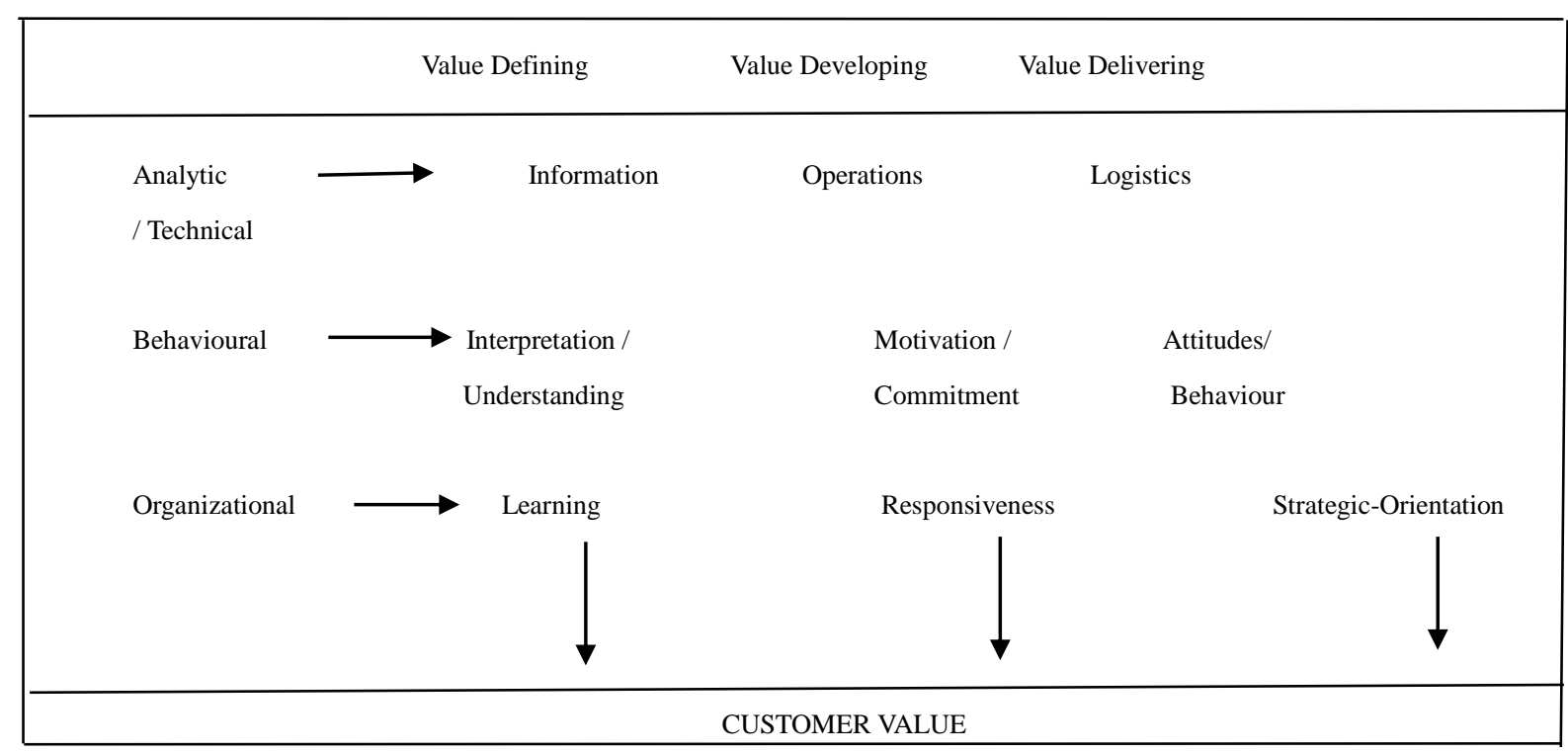

Figure 3. The Dimensions of Organizational Processes (Piercy, 1998)

Studies of implementation issues in small and medium organizations (Sashittal \& Wilemon, 1996; Sashittal \& Jassawalla, 2001) reveal that marketing strategy implementation involves translating strategic intentions into action steps, assigning relevant tasks and actions to people, ensuring that the tasks are executed as intended and accomplish predetermined objectives. The implementation tasks include organizational design configuration as needed, as well as managing an action oriented process that requires administration and control. Maintaining relevance between changing market events and marketing strategy content is a fundamental implementation challenge. Other challenges include defining appropriate action steps for implementation; enlisting support from other functional groups in the organization; dynamic adjustments to implementation plans. Dynamic adjustments includes taking into account day-to-day changes in customer preferences, competitive actions, and technological advances. Experientially, marketing implementation is seen as (1) sales management; (2) tasks and activity management - firefighting and stopgap activities; sales support and program development activities; (3) planning-implementation gestalt where planning is central to implementation.

\subsection{Marketing Implementation Tactics}

Tactics are concerned primarily with actions managers take to achieve the strategies they have chosen. Extant literature (Nutt, 1983; Nutt, 1986; Nutt, 1987) suggests that types of implementation approaches can be unilateral, manipulative or delegated. In unilateral tactics, managers rely on the use of power and announce the change overtly through an official edict. If problems ensue this is followed by a demonstration to show the plan works. Further problems are countered by a replacement approach to remove those blocking implementation and then a structural change to place likely implementers at key positions. In manipulative tactics, first there is the unfreezing or unlearning of past behaviour, then change is brought in to bring in new skills and behaviour and refreezing (reinforcing new patterns). In delegative tactics the aim is to get those in key positions to co-opt and participate to bring in the required implementation changes.

One of the key tasks for top management is to consistently and accurately communicate the strategic priority of the organization to functional level members for implementation, so that the implementation process does not break down due to lack of alignment between the top management and the organizational members. This shared understanding about strategic priorities is often called as 'strategic consensus.' Strategic consensus is a must for implementation success. Strategic consensus can be improved by improved communication between top management and marketing department that could also lead to improved functional performance and improved organizational performance. The flow of information will be both ways between the frontline and the top management. Frontline employees interact daily with customers and are in a good position to understand needs, wants and perceptions of customers. By vertical communication, top management get insights into this fertile source of information about the market. Strategic consensus could also be achieved by having strong communication networks within the organization through both formal and informal mechanisms (Rapert et. al, 2002).

Bourgeois and Brodwin (1984) have identified five process approaches to strategy implementation. They are as follows (Ferrell et al, 1998): 
a. The Commander Model. This model reflects a bias to centralized direction. It uses conventional analytical techniques to select strategic direction, and organizational power to command implementation. There is a dichotomy between the planner and implementer. It makes decision-making easier and reduces uncertainty as what is to be done. The disadvantages being that strategy formulators are far removed from targeted customers and this approach often creates employee motivation problems. This approach tends to work best when the firm has a powerful leader.

b. The Change Model. Here the manager is still the key player who communicates the firm's new priorities and gets work /tasks done, with the required organizational changes. Culture adaptation techniques are used to bring forth the changes. The manager in charge is more of an architect and politician. There is still a dichotomy between the planning and implementation and a 'power-at-the top' mentality.

c. The Collaborative Model: The manager acts as a coordinator and the emphasis are on team-building at a senior level in the organization. The advantages are that this approach moves some of the decision making authority closer to the front lines; lower level managers implementing strategy have a better idea of the strategy formation and hence can implement better. This involvement of the front line managers brings in greater motivation and commitment in the employees. The barrier between the strategists and implementers still remains. This approach tends to work best in complex, uncertain and highly unstable environments.

d. The Cultural Model: There is infusion of new corporate culture throughout the organization, with the manager acting as a coach. All employees participate in making decisions, and as a result the barrier between strategists and implementers are broken down. Marketing strategy is considered a part of the overall organizational vision. There is a good amount of decentralization called empowerment. Implementation problems are solved at the cost of much time in consensus decision making and culture building activities.

e. The Crescive Model: Bottom up strategy formation and implementation is encouraged, with adequate openness of the organization to new information being maintained. The abilities of the managers to create and implement strategies for business are drawn out by senior management.

\section{Postulates about Marketing Strategy Implementation}

Based on the conceptual study of the marketing strategy process and the examination of the nature of marketing strategy implementation using extant literature, a set of postulates are laid out which are checked for inferences using empirical study. The postulates include:

a. There must be a leader or group specifically earmarked for marketing strategy implementation. Associated with this leader or group, there must be an accountability and responsibility

b. Early on in the organization's history, the organization must do everything possible to succeed in implementation. This builds up a favorable precedent that instills confidence in the organization. In the case of start-ups success in implementation is ensured if the order-books are full. Inefficient sales teams could lead to implementation failures. Personal care must be taken by top-management to obtain and service the first order of every important customer.

c. The implementation structure could be different from the organization structure to take care of power, politics, resource deployment, accountability.

d. Sufficient funds must be set aside for execution. The execution process must not be hampered for want of funds.

e. Skills of taking the 'offering' to the market must be built into the implementation group. This includes forecasting skills, competitive intelligence, advertising and communication skills, and complaint management skills.

f. Trust is at the core of implementation process - between important group members. Role assignment and work allocation must be done with trust and faith

g. Marketing strategy implementation should be a natural evolution of marketing strategy formulation process. This means members of the formulation team should be equally well consulted if implementation is to succeed.

h. System of early warning / feedback should be outlined so that initial signs of difficulty / failure should be read and implementation path suitably changed; for example, there may be a need to go through agents/ dealers in addition to own showrooms if the required market share has to be attained.

i. A system of buying support from inside for implementation purpose would ease the process of implementation and lead to success. 
j. Processes of development of an organization extended family for implementation purpose with the critical value add processes taken into the central organization could lead to success.

k. Resource allocation should go hand in hand with implementation if implementation has to be effective.

1. Achieving functionalities in the market offerings is one of the aims of a good implementation process; for example a premium hotel such as Leela Penta, Bangalore, India, stresses on 'service par excellence' as one of its functionalities, then operations as an implementation process should be fine-tuned to achieve this functionality.

m. Good implementation arises partly from good relationships with customers, vendors, collaborators, and other stakeholders.

n. Good implementation occurs with the right mix of experts in formulation as well as implementation. An organization overloaded with either of the one category of formulators/implementers may result in a situation of too many cooks spoiling the broth or a lack of strategic vision.

o. A 'fetish for execution' motive could help an organization overcome implementation obstacles arising out of people interactions.

p. Coordination skills within and between the strategy process, people process, operations process are important for good implementation. Firms may attempt to obtain competitive advantage about implementation processes through causal ambiguity.

q. Reward and incentive schemes to corroborate the execution successes not only leads to good motivation, but also leads to goodwill among executives for future execution programs of an organization. A certain amount of hype about rewards and incentives may be useful.

r. Failures in implementation though not necessarily due to poor strategy, should be analyzed and corrective measures taken for future implementation programs.

s. It may be useful to think of marketing strategy implementation as a program as much as it is a process.

t. Management of market externalities is an important part of the implementation process. This includes government clearances, lobbying with government for specific provisions, and channel management programs.

u. Implementation will be successful if it is seen as a WIN-WIN procedure for the firm and its partners - be it dealers, collaborators, and suppliers.

v. Power and politics are influencers in the marketing strategy implementation process. Managers in charge of implementation should train themselves to work around these aspects rather than bypassing them.

w. Implementation involves resource expenditures and as such conflict is bound to arise. Managers should be able to resolve conflicts well.

x. Effectiveness of a marketing strategy implementation is influenced by the appropriate choice of 'market vs. hierarchy' for conducting their tasks.

y. The value proposition of the business needs to be carefully delivered to the customer through appropriate implementation processes.

z. Giving attention to competition - whom, when, and how - can lead to powerful market oriented implementation strategies.

\section{Empirical Verification}

\subsection{Himalaya Drug Company}

This company is an herbal health care company in India. Their insights are as follows:

One of the main marketing implementation problems they have faced is one of migration in the consumer perception from one category to another. One example is that of 'Complan' which was a pure prescription product in the 1970s and had to migrate to the OTC (over the counter) category by 2000 . The conversion to OTC markets was done through mass marketing techniques that built up visibility and availability. The second category is of pure herbal products like Ashwagandha which was marketed through big format stores and franchise outlets, to migrate from consumer products to Rx market. The migration of this category of pure herbs to the Rx category was faced with inhibition from the field force, as to how to take a popular brand to the doctor for his recommendation. A detailed brand presentation was made to doctors that included naming of herbs such as Ashwagandha to be Ashwagandha- Himalaya, gifts schemes for doctors, advertisement support for prints to trade, and conduct of several promotion campaigns such as diabetes campaign for diabetes drugs. In case of baby soap and baby oil, Herbal Actives mentioned in the product were used as differentiators and were supported by 
clinical trials. The main bottlenecks in migrating from consumer products to Rx market was that the stockists for the consumer products was different from the stockists for Rx market, their discounting structures was different. The whole process of migration was implemented much as a market development or market expansion route.

The main issue of marketing implementation is that of overcoming resistance to change. This they handled through the processes of repetitive communication, persuasion and awareness building to overcome resistance of doctor, chemist, medical representatives, and managers. Innovative activities of corporate marketing in terms of different promotional campaigns, with data on results obtained in trial markets convinced the executors of need and benefits of change, and the implementation change was brought about. In startups, power and politics is less as sales pressure is high. Power of implementation is more important than fund availability as funds are available from management for innovative activities. Skills of taking the 'offering to the market' is built through training.

The second main issue apart from overcoming resistance to change is the need for a measurement system to check the implementation process. The results of implementation should be properly measured and feedback given to the relevant nodes in the organization. Communication stands out as one of the processes for good implementation. This includes vertical communication through hierarchy, horizontal communication, networked communication through different nodes in the organization and lastly unofficial channels of communication. If these communication channels are effectively utilized along with political suaveness then it would lead to implementation success. For a marketing strategy to succeed it is important that the formulator should be aware of ground realities. Stretch targets to line managers are given to reduce politics and conflicts. This may however dampen enthusiasm. The choice of 'market vs. hierarchy' for implementation purposes depends on the orientation of the owner. Information feedback to implementation heads is kept up, through daily sales reports, ORG_IMS audits to monitor sales at stockist's levels. At Head Office level a prescription audit is also held. A successful leader is needed to champion the implementation process as mentioned in the first postulate of implementation in the previous section. The organization recruited a Sales Force Effectiveness Director, to connect the formulators and the implementers. Finally, trust plays a vital role in implementation.

\subsection{Airtel}

This is a cellular services company in India. Their insights are as follows:

The telecom market is volatile, influenced by market externalities which influence business forecasts drastically. One of the innovative measures is number portability. In the traditional systems the telecom firm owns the number. In number portability the customer owns the number and consequently can switch operators with greater ease, thereby making the market more deal prone. There are frequent changes in the market scenario owing to continuous marketing activity, technological advancements. SEC 'A' and ' $\mathrm{B}$ ' have been mobile for several years now. Monthly payout plays a critical role for SEC ' $C$ ', ' $D$ ', ' $E$ '. Other factors that influence new customers are (1) geographic expansion; (2) tariff competition; (3) distribution expansion; (4) entry cost. The firm carries on its implementation task using an annual plan and a five year plan, as well as an appropriate organizational structure as shown in Figure 4.

There is no requirement of a separate Marketing Implementation Director, as this function is handled by the Chief Operating Officer (COO) and the Marketing Head. Implementation is the key to success. Good Implementation of poor strategy is better than bad implementation of good strategy. Special events are a good method to achieving implementation milestones, and there are necessary flexibilities to bring out organizational changes to get these special events conducted. In this organization the planner and implementer are clubbed into one. The heads of the various departments coordinate on basis of trust. Information systems on market are exhaustive. Good paths exist to early warning /correction systems. The firm operates through partners for delivering solutions to the customer. The firm operates in Karnataka through the core pillars of network superiority and customer delight. The value proposition is maintained through a service assurance department. Feedback from customer on service quality is obtained by third party agencies. Coordination skills in the implementation process are more important than individual skills. Buy-in is a very important feature of the implementation. Efforts are made to buy-in all departments with respect to the Annual Plan. Cross departmental buy-in is important, so that the firm as an aggregate is not at loss. 
Chief Executive Officer (Karnataka Circle)

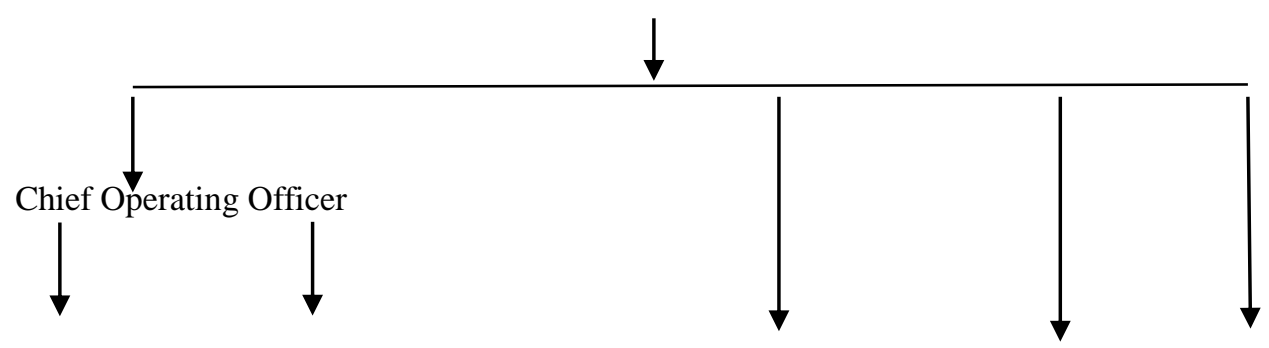

Sales \& Marketing Customer Service Technical Networks Finance Info Tech

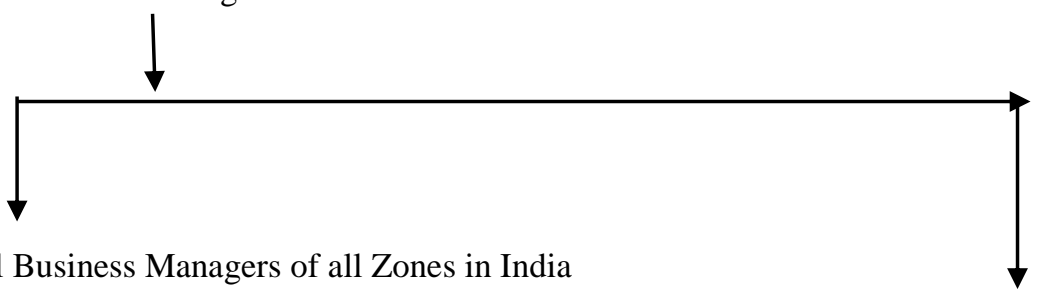

Zonal Business Managers of all Zones in India

\author{
Marketing Team \\ (Customer Acquisitions, Revenue and Usage, Commercial \\ Marketing, Value Added Services, Roaming)
}

Figure 4. Organizational Structure at Airtel

\title{
6.3 Britannia Industries Ltd.
}

This is a leading FMCG (Fast Moving Consumer Goods) Company based in Bangalore, India. Their insights are that marketing strategy and consequently its implementation is not insular, as other functional strategies will have their influence. Marketing strategy is not one monolith. There are different sub-sections or components owing to the multi-divisional structure of the organization. There are intelligence inputs to execution and the formulation-execution interface is dynamic. Formulators could be implementers. Funds are a limited part of the organizational requirement for execution. Also included is a buildup of time, money, processes, and skills. Managing relationships and managing market externalities well is a positive factor to marketing execution success. Marketing strategy implementation in the world is stochastic in nature. How the firm engages with uncertainties during execution has a bearing on success of the execution effort. Examining variability, leveraging variability and adapting to variability is important. Execution also involves examining the consumer aspects to be able to tune the deliverables that are important from the consumer point of view.

\subsection{Laguna Clothing}

This firm is an apparel exporting company (formal dress shirts) based out of Bangalore. Their insights are that strategy formulation is easier due to the availability of special tools and techniques as well as consultants who are able to spare attention. Execution on the other hand has failures due to failures of implementers to understand organizational dynamics, misjudgment of abilities of implementing group and poor communication during the execution stage. Buy in is not necessary for implementing strategy. Leader is required for overseeing execution of tasks as well as acting as an integrator of strategy formulation and strategy implementation aspects. This integration is one of the most important parts of business marketing strategy. Depending on market context and stage of firm, marketing strategy may or may not be the lead strategy. Initial efforts in implementation considerations of a start-up business could be in management recruitment and quality achievement. Laguna Clothing's initial strategy formulation design was in high end dress shirts. However there was difficulty of getting orders for the high end position. It was relatively easier to sell less expensive / cheap formal shirts. However it was the leader's responsibility of selling high end fabric shirts despite difficulty of order getting. This is where the leader should integrate and position the firm in the right direction. Further the customers have to be communicated of the high end position. Structure for implementation could be different from the organizational structure, but the implementation structure and the organizational structure should be well integrated into one another at the Leader's level, and if there is a radically different marketing strategy then a new organization has to be created. Rewards and incentives to be implemented are aligned with the marketing strategy formulation. Rewards, pay incentives, persuasion, power, politics is the reality of the organization and implementation managers should know to effectively use these structures for achieving good execution. 


\section{Discussion}

Marketing Strategy Implementation is seen by the marketing managers in charge of execution as a process as well as a program. In such a case implementation could also be seen as an event management program, for example launch of a new brand. Though marketing strategy could be postulated as a lead functional strategy owing to the requirement of understanding customer needs and wants, business managers are of the opinion that this is not necessarily true. Quality management and people recruitment strategies could be the initial / lead processes to be executed. Leadership is a key to Marketing Strategy Implementation (MSI). The strategy formulation and strategy implementation strategies become integrated at the leader level and this is important for success. Bourgeois and Brodwin (1984) identify five different models of implementation - Commander, Change, Collaborative, Cultural and Crescive. However the organization could evolve through these five models and also the implementation model could change from one implementation process to another depending on sensitivity of the market context, the marketing strategy being executed and on the value proposition being offered. Making an organization ready to accept 'change' and move accordingly is very important as it is sometimes said that "nothing is more permanent than change'. Change here includes culture change. Achieving desired functionalities to customer is as important as executing strategy. Customer end success is achieved through satisfaction and delight of customer end functionalities. Good relationships with dealers, collaborators and other market externality organizations are a prerequisite to implementation success. At the same time relationship risk has to be managed by not getting too much entangled with customer emotions. Developing information asymmetry advantages through suitable interactions with customers as a part of relationship marketing exercise during implementation could be a facilitator of competitive advantage. Communication and signaling in both horizontal and vertical positions in an organization should be clear and simple to achieve better effectiveness and efficiency during the implementation process. Distinctions between planners and implementers are useful for large organizations in stable market environments. In emerging markets it is useful to integrate both aspects into the decisions maker's roles. Brands and corporate reputation is built during the implementation processes. This means the quality of the implementation personnel should be adequately looked into. Hiring key people for important positions with result oriented mindset and skills are important for implementation success. Budgets have to be not only laid out but also sustained in case of overruns. This means top management commitment or deep pockets could aid in success of an implementation program. Power, politics, and conflict resolution mechanisms should be incorporated into the implementer's mindset. Managers always face a choice between market and hierarchy for executing the strategy. This is all the more important in these days of global outsourcing.

Four areas of marketing strategy implementation / execution emerges from the discussion: (i) leadership issues; (ii) systems / structure issues; (iii) people issues; (iv) performance issues. Success of implementation is driven on the formulation side by (1) how well the value proposition of the business is formulated; (2) how well the opportunity analysis has been done; and (3) how well competitor moves are conjectured. Implementation success of marketing strategy is also influenced by an effective marketing control applied on the implementation process.

\section{Acknowledgements}

This paper is a development of an empirical study undertaken by the author, for the 8th International Marketing Trends Congress at European School of Management (ESCP-EAP), Paris, France, January, 2009. The author thanks the management officials in the following companies whose offices are in Bangalore, India - Airtel Ltd., Britannia Industries Ltd., Himalaya Drug Co., and Laguna Clothing Ltd.

\section{References}

Aaker, D. A., \& Damien, M. (2010). Strategic market management: Global perspectives. Wiley, India. Argyris, C. (1985). Strategy, change and defensive routines. New York, Ballinger-Harper and Row.

Bonoma, T. V. (1984). Making your marketing strategy work. Harvard Business Review, March-April, 62(2).

Bossidy, L., \& Ram, C. (2002). Execution: The discipline of getting things done. Crown Business, New York.

Bourgeois, L., \& Brodwin, D. (1984). Strategic Implementation: Five approaches to an elusive phenomenon.' Strategic Management Journal, 5(3). http://dx.doi.org/10.1002/smj.4250050305

Corey, E. R., \& Stephen, H. S. (1971). Organizing strategy: A marketing approach. Boston: Harvard Business School, Division of Research.

Ferrell, O., Michael, D. H., George, H. L. J., \& David, L. (1998). Marketing strategy. Dryden Press.

Hrebiniak, L. G. (2005). Making strategy work: Leading effective execution and change. Wharton School Publishing. 
Nutt, P. C. (1983). Implementation approaches for project planning. Academy of Management Review, 8(4). http://dx.doi.org/10.2307/258261

Nutt, P. C. (1986). Tactics of Implementation. Academy of Management Journal, 29(2). http://dx.doi.org/10.2307/256187

Nutt, P. C. (1987). Identifying and appraising how managers install strategy. Strategic Management Journal, 8(1). http://dx.doi.org/10.1002/smj.4250080102

Piercy, N. F. (1998). Marketing Implementation: The implications of marketing paradigm weakness for the strategy execution process.' Journal of Academy of Marketing Science (summer), 26(3). http://dx.doi.org/10.1177/0092070398263004

Quelch, J. A. (1992). Marketing implementation. Note - Harvard Business School.

Rapert, M. I., Anne, V., \& Judith, A. G. (2002). The strategic implementation process. Evoking strategic consensus through communication.' Journal of Business Research, 55(4). http://dx.doi.org/10.1016/S0148-2963(00)00157-0

Sashittal, H. C., \& Avan, R. J. (2001). Marketing Implementation in smaller organizations: Definition, framework and propositional inventory.' Journal of Academy of Marketing Science (winter), 29(1). http://dx.doi.org/10.1177/0092070301291004

Sashittal, H. C., \& David, W. (1996). Marketing Implementation in Small and Midsized Industrial Firms - An exploratory study.' Industrial Marketing Management, 25(1). http://dx.doi.org/10.1016/0019-8501(95)00066-6

Whittington, R., \& Richard, W. (1992). Professional Ideology and Marketing Implementation. European Journal of Marketing, 26(1). http://dx.doi.org/10.1108/03090569210007792

\section{Copyrights}

Copyright for this article is retained by the author(s), with first publication rights granted to the journal.

This is an open-access article distributed under the terms and conditions of the Creative Commons Attribution license (http://creativecommons.org/licenses/by/4.0/). 